Huseynov 5. I., Dasimov 5. Yu.

\title{
NUMERICAL SOLUTION OF THE OPTIMAL SPEED PROBLEM WITH A PHASE CONSTRAINT FOR ONE PARABOLIC EOUATION
}

Розглянуто чисельний метод розв'язання задачі на оптимальну швидкодію з фазовим обмеженням для параболічного рівняння зі змінними коефіцієнтами, що описує процеси теплопровідності в неоднорідних пористих середовищах. Чисельна реалізачія алгоритму здійснена методом кінцевих різниць на нерівномірній сітиі. Запропонований метод може бути застосований для оптимального визначення параметрів прочесів теплопровідності і дифузї в неоднорідних середовищах.

Ключові слова: параболічне рівняння, завдання швидкодіi, оптимальне управління, штрафний функціонал, градієнт функціоналу.

\section{Introduction}

For practice, speed problems are of great interest, when it is necessary to realize technologically desirable temperatures of a medium with the specified accuracy in the shortest possible time. The use of tertiary methods for increasing oil production [1] poses a number of problems, the solution of which is somehow connected with the optimal organization of the processes of impact on the reservoir and their management. Investigation of non-isothermal processes in porous media [2, 3] shows that, depending on the real properties of liquids and the reservoir, there is a technologically desirable temperature distribution in the formation, in which the displacement process takes place more efficiently. In this regard, there is a need to determine such regimes and terms of impact on the formations, which, with minimal costs of material thermal resources, would provide the maximum effect. Therefore, the theoretical study of heat transfer processes, the determination on this basis of optimal regimes and terms of thermal exposure, is undoubtedly of great theoretical and practical interest.

\section{The object of research and its technological audit}

The object of research is an iterative numerical method for solving problems for optimal speed with phase constraint for equations of parabolic type with variable coefficients, describing the processes of thermal conductivity in porous media.

Mathematical modeling of non-isothermal filtration processes of a homogeneous incompressible fluid in an inhomogeneous formation shows [3] that the determination of the temperature distribution in a reservoir in dimensionless variables can be reduced to the solution of the boundary value problem:

$$
\begin{aligned}
& \frac{1}{x^{n}} \frac{\partial}{\partial x}\left(x^{n} k(x) \frac{\partial u}{\partial x}\right)+\frac{q(t)}{x^{n}} \frac{\partial u}{\partial x}-\beta(t) u+f(x, t)= \\
& =c(x) \frac{\partial u}{\partial t},(x, t) \in G=\left\{x_{c}<x<x_{R}, 0<t \leq T\right\},
\end{aligned}
$$

$$
\begin{aligned}
& u(x, 0)=\varphi(x), r_{c} \leq x \leq r_{R}, \\
& \sigma_{1} u\left(x_{c}, t\right)-\sigma_{2} u_{x}\left(x_{c}, t\right)=g(t), 0<t \leq T, \\
& \sigma_{3} u\left(x_{R}, t\right)+\sigma_{3} \alpha u_{x}\left(x_{R}, t\right)=v(t), 0 \leq t \leq T,
\end{aligned}
$$

where $u(x, t)$ - the average formation temperature; $\varphi(x)-$ initial temperature distribution; $k(x), c(x), q(t), \beta(t)-$ known continuous functions - thermophysical characteristics of a liquid-saturated porous medium; $f(x, t)$ - density of thermal sources; $g(t)$ - temperature $\left(\sigma_{1}=1, \sigma_{2}=0\right)$ or heat flux at the boundary $r=r_{c} ; v(t)-$ temperature $\left(\sigma_{3}=1, \sigma_{4}=0\right)$ or power $\left(\sigma_{3}=1, \sigma_{4}=0\right)$ of the heat source at the boundary $r=r_{R} . n=0$ corresponds to a plane-parallel one; $n=1-$ flat radial filtration.

It is necessary to determine such operation mode of thermal sources, so that the temperature distribution of the formation specified from the technological conditions with the specified accuracy is reached in a minimum time. The mathematical formulation of the problem consists in determining such controls $g(t), v(t), f(x, t)$ and functions $u(x, t)$ satisfying conditions (1) $-(4)$, with constraints:

$$
\begin{aligned}
& g_{\min } \leq g(t) \leq g_{\max }, \\
& v_{\min } \leq v(t) \leq v_{\max }, \\
& f_{\min } \leq f(t) \leq f_{\max }, \\
& u(x, t) \leq u_{\max },
\end{aligned}
$$

that for a given function $u^{*}(x)$ and constant $\delta \geq 0$, the inequality:

$$
\int_{x_{c}}^{x_{R}}\left(u(x, T)-u^{*}(x)\right)^{2} x^{n} \mathrm{~d} x \leq \delta
$$

is performed in the minimum time $T, g_{\min }, g_{\max }, v_{\min }, v_{\max }$ $f_{\min }, f_{\max }$ - specified numbers characterizing the limiting possibilities of thermal sources; $u_{\max }-$ maximum permissible temperature value. 
Controls $g(x, t), v(t), \quad f(t)$ will be sought in the set of piecewise-continuous functions that satisfy conditions (5) almost everywhere. Let's denote this set by $F$. For fixed $g(t)$, $v(t), f(t) \in F$ the corresponding solution [5] $u=u(x, t)$ is determined from the boundary value problem (1)-(4). Let's assume that this solution exists and is unique.

Let's note that many other physical processes [4] are also described by the mathematical model (1)-(4), therefore, the developed numerical method can be applied to solving analogous speed problems for these processes

\section{The aim and objectives of research}

The aim of research is development of a numerical method for solving the problem of optimal speed with phase constraint for a parabolic equation with variable coefficients, describing the processes of thermal conductivity in inhomogeneous porous media, with plane-parallel and plane-normal filtration.

To achieve this aim, it is necessary to solve such problems:

1. To solve problems using first-order optimization methods, derive analytical formulas for the gradient components of the functional with the respect to the control parameters, through which an iterative process of finding the optimal control for speed will be built.

2. Based on numerical experiments, discuss the computational implementation of the proposed methodology and give practical recommendations on its application.

\section{Research of existing solutions of the problem}

It is known that the study of heat conduction processes leads to problems for a linear parabolic equation only if small intervals of temperature change are considered [4]. Therefore, there arises the need to solve problems for optimal speed, not only with limiting the temperature of the control thermal sources, but also on the temperature distribution at all points. Such problems arise also in the study of thermal processes, when superheating of the medium above a certain critical temperature is not permissible [2, 4].

In this regard, considerable interest is the development of effective computational algorithms for solving specific problems of speed with phase constraint for equations of parabolic type.

Problems of optimal control and speed for partial differential equations, including those for parabolic equations, are devoted to extensive scientific literature [1-10]. For some classes of such problems, questions of the existence and uniqueness of the optimal control for speed are investigated, necessary and sufficient conditions for optimality are obtained, methods for their solution are developed [5-9]. Numerical methods for solving time-optimal problems for equations of parabolic type are devoted to [7-9], in which problems without a phase constraint are mainly considered.

\section{Methods of research}

Let there exist such $T$ and such $g(t), v(t), f(t) \in F$, for which, under conditions (1)-(6), inequality (7) is fulfilled, which let's call respectively, admissible time and controls. Time $T=T_{o n}$ and functions $g_{o n}(t), v_{o n}(t), f_{o n}(t) \in F$, being the solution of problem (1)-(7), are optimal in terms of speed.

Let's consider the following auxiliary optimal control problem: for a fixed $T$ find, such $g(t, T), v(t, T), f(x, t, T) \in F$ that, under the conditions (1)-(6), the functional:

$$
\Phi(g, v, f)=\int_{x_{c}}^{x_{R}}\left(u(x, T)-u^{*}(x)\right)^{2} x^{n} \mathrm{~d} x,
$$

has its least possible value. This problem is of independent interest, similar problems have been studied by many authors $[6,7]$. Let's also assume that for $T$ the problem of finding the minimum of the functional (8) under the conditions (1) $-(6)$ has a solution.

The method of penalty functionals is applied to the solution of the optimal control problem for a fixed $T$ [7]. The functional is introduced:

$$
J(g, v, f)=\Phi(g, v, f)+A_{k} P(g, v, f),
$$

where

$$
\begin{aligned}
& P(g, v, f)=\int_{0}^{T} \int_{x_{c}}^{x_{R}}\left(\max \left\{u(x, t)-u_{\max }\right\}\right)^{2} \mathrm{~d} x \mathrm{~d} t, \\
& \lim _{k \rightarrow \infty} A_{k}=\infty
\end{aligned}
$$

(for example, $A_{k}=10^{k}$ ).

To solve the problem of minimizing the functional (9) at $T$, using approximate first-order optimization methods [7], an analytic formula for the gradient of the functional (10) is derived.

$$
\begin{aligned}
& \operatorname{grad} J=\left(J_{g}, J_{v}, J_{f}\right)=\left(\sigma_{1} x_{c}^{n} k\left(x_{c}\right) \frac{\partial y\left(x_{c}, t\right)}{\partial x}-\right. \\
& -\sigma_{2} x_{c}^{n} x_{c} k\left(x_{c}\right) y\left(x_{c}, t\right)-\sigma_{3} x_{R}^{n} k\left(x_{R}\right) \frac{\partial y\left(x_{R}, t\right)}{\partial x} \\
& \left.+\sigma_{4} x_{R}^{n} k\left(x_{R}\right) y\left(x_{R}, t\right), \quad \int_{x_{c}}^{x_{R}} x^{n} y(x, t) d x\right),
\end{aligned}
$$

where $y(x, t)$ - solution of the boundary value problem;

$$
\begin{aligned}
& \frac{1}{x^{n}} \frac{\partial}{\partial x}\left(x^{n} \frac{\partial y}{\partial x}\right)-\frac{q(t)}{x^{n}} \frac{\partial y}{\partial x}-\beta(t) y(x, t)+ \\
& +2 A_{k} \max \left\{\left(u(x, t)-u_{\max }\right) ; 0\right\}=-c(x) \frac{\partial y}{\partial t}, \\
& (x, t) \in G^{\prime}=\left\{r_{c}<r<r_{R}, 0 \leq t<T\right\}, \\
& y(x, T)=2\left(u(x, T)-u^{*}(x)\right) / c(x), x_{c} \leq x \leq x_{R}, \\
& \sigma_{1} y\left(x_{c}, t\right)+\sigma_{2}\left(x_{c}^{n} k\left(x_{c}\right) \frac{\partial y\left(x_{c}, t\right)}{\partial x}-q(t) y\left(x_{c}, t\right)\right)=0, \\
& \sigma_{3} y\left(x_{R}, t\right)-\sigma_{n}\left(x_{R}^{n} k\left(x_{R}\right) \frac{\partial y\left(x_{R}, t\right)}{\partial x}-q(t) y\left(x_{R}, t\right)\right)=0, \\
& 0 \leq t \leq T .
\end{aligned}
$$

Consequently, to calculate the gradient of the functional (9) for fixed $g(t), v(t), f(t)$ it is necessary to solve the boundary value problems (1)-(4), (11) to determine the functions $u(x, t), y(x, t)$ and substitute them in (10). 
For a numerical solution of optimal control problems for a fixed $T$, a discrete analogue of the problem is constructed by the method of finite differences on an uneven grid, which is constructed on the basis of a priori information on the properties of the solution of boundary value problems. In view of the fact that large gradients of functions $u(x, t)$, $y(x, t)$ are achieved near the boundary points $x=x_{c}$ and $x=x_{n}$ it is advisable to use a non-uniform grid with respect to the spatial variable that takes this property into account. In this connection, it is necessary to thicken the grid nodes with the respect to the variable $x$ in the vicinity of these points. This principle is laid in the basis of the grid construction:

$$
\begin{aligned}
& \bar{\omega}_{i, j}=\left\{\left(x_{i}, t_{j}\right): x_{i+1}=x_{i}+h_{i+1},\right. \\
& i=0,1, \ldots, N-1, x_{0}=x_{c}, x_{N}=x_{R}, \\
& t_{j+1}=t_{j}+\tau_{j+1}, j=0,1, \ldots, M-1 ; \\
& \left.t_{0}=0, t_{M}=T\right\} .
\end{aligned}
$$

Using the implicit two-layer conservative scheme [4, 10] and retaining the previous notation for grid functions, the differential problems (1)-(4) and (11) can be approximated by the following difference problems:

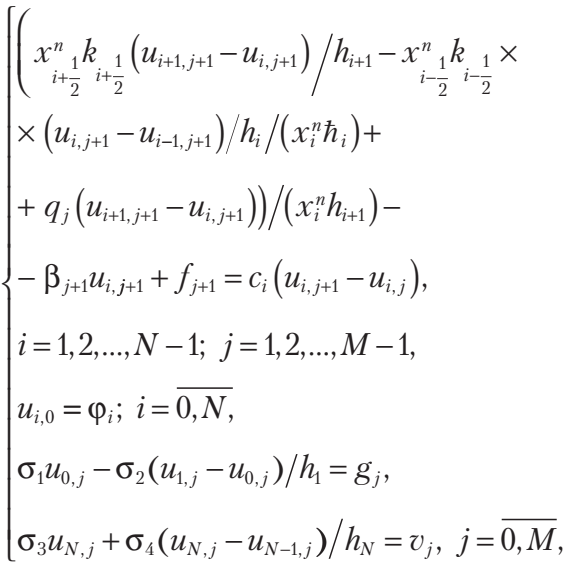

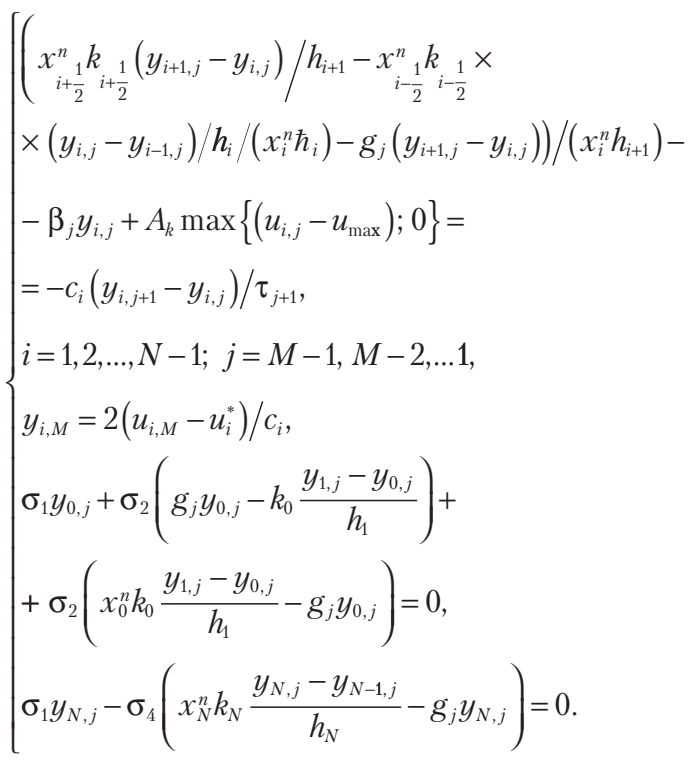

The discrete analogue of the gradient of the functional (13) has the form:

$$
\begin{aligned}
& \operatorname{grad} J=\left(J_{q_{j}}, J_{v_{j}}, J_{f_{j}}\right)= \\
& =\left(\sigma_{1} x^{n} k_{0} \frac{y_{1, j}-y_{0, j}}{h_{1}}-\sigma_{2} x_{0}^{n} k_{0} y_{0, j}, \sigma_{3} x_{N}^{n} k_{N} \frac{y_{N}-y_{N-1}}{h_{N}}+\right. \\
& \left.+\sigma_{4} x_{N}^{n} k_{N} y_{N, j} \sum_{i=0}^{N-1} h_{i}\left(x_{i-1}^{n} y_{i-1, j}+x_{i}^{n} y_{i, j}\right) / 2\right), \\
& i=\overline{1, N}, j=\overline{0, M} .
\end{aligned}
$$

The functional (10) is calculated by the quadrature formula of trapezoids.

The problems (12), (13) are linear with respect to the values of the grid functions $u_{i, j+1}$ and $y_{i, j}$ and are solved by the sweep method. Since these schemes are absolutely stable [10], the step $\tau_{j}$ is chosen only for reasons of accuracy.

Thus, the solution of the optimal control problem for fixed $T$ is reduced to the construction of sequences $\left\{g_{j}\right\}$, $\left\{v_{j}\right\},\left\{f_{j}\right\},(j=\overline{0, M})$ by optimization methods:

- by the conditional gradient method (CGM) and the gradient projection (GPM), starting with some initial approximations;

- the step of the gradient methods is determined from the condition of a monotone decrease of the functional by the bisection method [7].

Let's note that similar problems with two control functions are considered in [11-14].

The speed problem is solved using the following algorithm [12]:

Let

$$
\begin{aligned}
& T^{(m)}>0, \quad g\left(t_{j}, T^{(m)}\right), \quad v\left(t_{j}, T^{(m)}\right), \\
& f\left(t_{j}, T^{(m)}\right), \quad m=1,2, \ldots, \quad j=0,1,2, \ldots, M,
\end{aligned}
$$

solution of the auxiliary problem for $T^{(1)}, g\left(t_{j}, T^{(1)}\right), v\left(t_{j}, T^{(1)}\right)$, the following condition is satisfied:

$$
\min J(g, v, f) \leq \delta .
$$

If (15) is satisfied for $T^{(m)}, g\left(t_{j}, T^{(m)}\right), v\left(t_{j}, T^{(m)}\right), f\left(t_{j}, T^{(m)}\right)$ $(j=0,1,2, \ldots, M)$ then the following time is taken as the approximation:

$$
T^{(m+1)}=T^{(m)}-\frac{T^{(1)}}{2^{m}},
$$

else

$$
T^{(m+1)}=T^{(m)}+\frac{T^{(1)}}{2^{m}}, m=1,2, \ldots .
$$

Iterations over time continue until some $m=m_{*}$, at which the following condition is fulfilled:

$$
\frac{T_{1}}{2^{m_{*}}} \leq \varepsilon
$$

where $\varepsilon-$ sufficiently small positive number. If, when $T=T^{\left(m_{*}\right)}(15)$ is satisfied, then $T_{0 n}=T^{\left(m_{*}\right)}$, otherwise:

$$
T_{0 n}=T^{(i \cdot)}, \quad T_{0 n}=T^{\left(m^{*}\right)}+\frac{T^{(1)}}{2^{m_{*}-1}},
$$

and for the optimal speed of control are taken:

$$
g_{0 n}\left(t_{j}\right)=g\left(t_{j}, T_{o p}\right), v_{0 n}\left(t_{j}\right)=g\left(t_{j}, T_{o n}\right), f_{0 n}\left(t_{j}\right)=g\left(t_{j}, T_{o n}\right) .
$$


In connection with the fact that for each $T^{(m)}$ the corresponding optimal control problem is solved by the first-order optimization method, whose convergence essentially depends on the initial approximations:

$$
g^{(0)}\left(t_{j}, T^{(m)}\right), \quad v^{(0)}\left(t_{j}, T^{(m)}\right), \quad f^{(0)}\left(t_{j}, T^{(m)}\right) .
$$

The following methods of choosing zero approximations for controls are considered:

a) for all

$$
\begin{aligned}
& T^{(m)}(m=1,2, \ldots), \quad g^{(0)}\left(t_{j}, T^{(m)}\right)=g_{H}\left(t_{j}\right), \\
& v^{(0)}\left(t_{j}, T^{(m)}\right)=v_{H}\left(t_{j}\right), \quad f^{(0)}\left(t_{j}, T^{(m)}\right)=f_{H}\left(t_{j}\right), \\
& j=0,1,2, \ldots, M, \quad 0 \leq t \leq T^{(i)},
\end{aligned}
$$

where $g_{H}\left(t_{j}\right), v_{H}\left(t_{j}\right)$ and $f_{H}\left(t_{j}\right)$ - specified grid functions.

b) let

$$
\begin{aligned}
& g^{(0)}\left(t_{j}, T^{(m)}\right)=g_{H}\left(t_{j}\right), \quad v^{(0)}\left(t_{j}, T^{(m)}\right)=v_{H}\left(t_{j}\right), \\
& f^{(0)}\left(t_{j}, T^{(m)}\right)=f_{H}\left(t_{j}\right), \text { at } T=T^{(m)}, 0 \leq t_{j} \leq T^{(m)} .
\end{aligned}
$$

Zero approximations for $m=1,2, \ldots$ are given by the formulas:

$$
\begin{aligned}
& g^{(0)}\left(t_{j}, T^{(m+1)}\right)=g^{(m)}\left(p^{(m)} t_{j}, T^{(m)}\right), \\
& v^{(0)}\left(p^{(m)} t_{j}, T^{(m+1)}\right)=v^{(m)}\left(p^{(m)} t_{j}, T^{(m)}\right), \\
& f^{(0)}\left(t_{j}, T^{(m+1)}\right)=f^{(m)}\left(p^{(m)} t_{j}, T^{(m)}\right), \\
& 0 \leq t_{j} \leq T^{(m)} .
\end{aligned}
$$

With this choice of initial approximations, the structure of the optimal controls found at the $m$-th iteration is preserved.

\section{Research results}

The convergence of the iteration process for solving the time-optimal problem can be proved similarly to the proof of the convergence of the binary division method for finding the extremum of functions of one variable [7]. It is assumed that condition (15) is fulfilled for all $T^{(m)}>T_{o n}$, and for $T^{(m)}<T_{o n}$ this condition the condition is not fulfilled $[5,8]$.

Let's give a typical example of the numerical experiments performed at:

$$
\begin{aligned}
& k(x)=x+1, \quad q(t)=1, \quad \beta=0, \quad c(x)=2 x, \\
& f(t)=0, \quad u_{\max }=5, \quad \varphi(x)=0.001, \quad x_{c}=0.001, \\
& x_{R}=1, \quad \sigma_{1}=\sigma_{3}=1, \quad \delta=0.005, \quad \varepsilon=10^{-4} .
\end{aligned}
$$

In numerical experiments, a non-uniform grid with the respect to $x$ is used, the nodes of which are shown in Table 1.

Calculations are carried out at:

$$
\tau_{j}^{(m)}=\frac{T^{(1)}}{M} \quad \text { and } \quad \tau_{j}^{(m)}=\frac{T^{(m)}}{M}, \quad m=1,2, \ldots .
$$

Table 1

The non-uniform grid with the respect to the spatial variable

\begin{tabular}{|c|c|c|c|c|c|c|}
\hline \multicolumn{7}{|c|}{ Grid nodes with respect to the variable $x$} \\
\hline 0.0010 & 0.0020 & 0.0030 & 0.0040 & 0.0050 & 0.0060 & 0.0080 \\
\hline 0.0120 & 0.0200 & 0.0360 & 0.0680 & 0.1000 & 0.1500 & 0.2000 \\
\hline 0.2500 & 0.3000 & 0.3500 & 0.4000 & 0.4500 & 0.5000 & 0.5500 \\
\hline 0.6000 & 0.6500 & 0.7000 & 0.7500 & 0.8000 & 0.8500 & 0.9000 \\
\hline 0.9320 & 0.9640 & 0.9800 & 0.9880 & 0.9920 & 0.9940 & 0.9950 \\
\hline 0.9960 & 0.9970 & 0.9980 & 0.9990 & 1.0000 & - & - \\
\hline
\end{tabular}

Let's note that in the first case the step $\tau_{j}^{(m)}=T^{(1)} / M=$ $=$ const, and in the second case the step $\tau_{j}^{(m)}$ changes at each iteration in time, but is uniform for a fixed $T^{(m)}$, $(m=1,2, \ldots)$. The results of numerical calculations show the expediency of choosing a step in time by this method.

Taking into account that the optimal control speed is «relay» function [5], a quasi-real (test) numerical experiment is performed in which, first by the finite difference method, the direct boundary value problem (1)-(4) is solved for the selected:

$$
g\left(t_{j}\right)=g^{*}\left(t_{j}\right), v\left(t_{j}\right)=v^{*}\left(t_{j}\right)
$$

where

$$
g^{*}\left(t_{j}\right)=v^{*}\left(t_{j}\right)= \begin{cases}8, & 0 \leq t_{j} \leq \theta, \\ 1, & \theta<t_{j} \leq T,\end{cases}
$$

where $T=0.06, \theta=0.055$ and $u^{*}(x)=u(x, T)$. In the speed problem, the initial time $T^{(1)}=0.24$, is taken, step by time:

$$
\tau_{j}^{(m)}=\frac{T^{(m)}}{M}, M=120 .
$$

The results of the calculations are shown in Tables 2,3 and in Fig. 1-5.

Table 2

Iterations over time, option a

\begin{tabular}{|c|c|c|c|c|c|c|c|}
\hline \multirow{2}{*}{$m$} & \multirow{2}{*}{$T^{(m)}$} & \multicolumn{3}{|c|}{ CGM } & \multicolumn{3}{|c|}{ CPM } \\
\cline { 3 - 8 } & & $J^{(0)}$ & $n$ & $J^{(n)}$ & $J^{(0)}$ & $n$ & $J^{(n)}$ \\
\hline 1 & 0.24 & 1.028593 & 30 & 0.004731 & 2.462947 & 14 & 0.005812 \\
\hline 2 & 0.12 & 0.533703 & 51 & 0.002331 & 2.905619 & 44 & 0.003639 \\
\hline 3 & 0.06 & 2.514059 & 77 & 0.000383 & 2.510189 & 65 & 0.000345 \\
\hline 4 & 0.03 & 2.643062 & 85 & 0.584954 & 2.640859 & 79 & 0.585478 \\
\hline 5 & 0.045 & 2.428016 & 98 & 0.119878 & 2.425056 & 97 & 0.119808 \\
\hline 6 & 0.0525 & 2.441755 & 110 & 0.026341 & 2.345241 & 108 & 0.024523 \\
\hline
\end{tabular}

Note: $m$ - iteration number at $T ; n$ - number of iterations in optimal control problems at $T^{(m)}$

Table 3

Iterations over time, option $b$

\begin{tabular}{|c|c|c|c|c|c|c|c|}
\hline \multirow{2}{*}{$m$} & \multirow{2}{*}{$T^{(m)}$} & \multicolumn{3}{|c|}{ CGM } & \multicolumn{3}{|c|}{ CPM } \\
\cline { 3 - 8 } & & $J^{(0)}$ & $\pi$ & $J^{(n)}$ & $J^{(0)}$ & $\Pi$ & $J^{(n)}$ \\
\hline 1 & 0.24 & 1.028593 & 30 & 0.004731 & 2.462947 & 14 & 0.005812 \\
\hline 2 & 0.12 & 0.096914 & 44 & 0.001274 & 0.208324 & 27 & 0.004827 \\
\hline 3 & 0.06 & 0.008936 & 56 & 0.000435 & 0.04313 & 39 & 0.000414 \\
\hline 4 & 0.03 & 0.594984 & 67 & 0.584253 & 0.598559 & 50 & 0.584176 \\
\hline 5 & 0.045 & 0.124654 & 76 & 0.119878 & 0.123654 & 58 & 0.119844 \\
\hline 6 & 0.0525 & 0.027892 & 81 & 0.027796 & 0.027742 & 64 & 0.027480 \\
\hline
\end{tabular}

Note: $m$ - iteration number at $T ; n$ - number of iterations in optimal control problems at $T^{(m)}$. 
Tables 2 and 3 show the values $T^{(m)}$, the value of the functional $J^{(0)}$ for initial approximations for control, the minimum values $\min J^{(n)}$ in optimal control problems for $T^{(m)}(m=1,2, \ldots)$, obtained by choosing the initial approximations in the ways $a$ and $b$, respectively. The optimal control problems for a fixed $T^{(m)}$ are solved by the conditional gradient (MUG) and the gradient projection (PGM) methods $g^{(0)}\left(t_{j}, T^{(m)}\right)=g_{\min }, v^{(0)}\left(t_{j}, T^{(m)}\right)=v_{\min }$, $g^{(0)}\left(t_{j}, T^{(m)}\right)=g_{\min }, v^{(0)}\left(t_{j}, T^{(m)}\right)=v_{\min }, m=1,2, \ldots$.

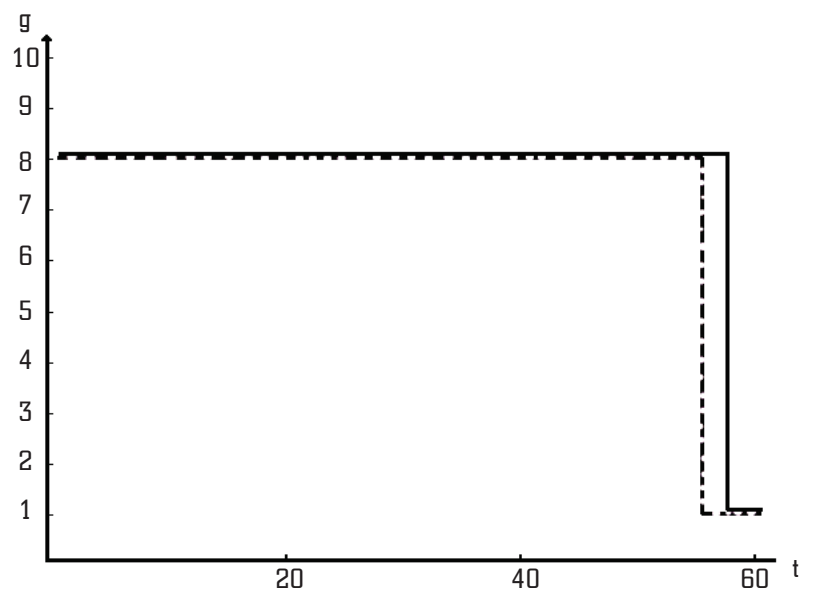

Fig. 1. Optimal speed control using conditional gradient method: $-g\left(t, T_{o n}\right)$

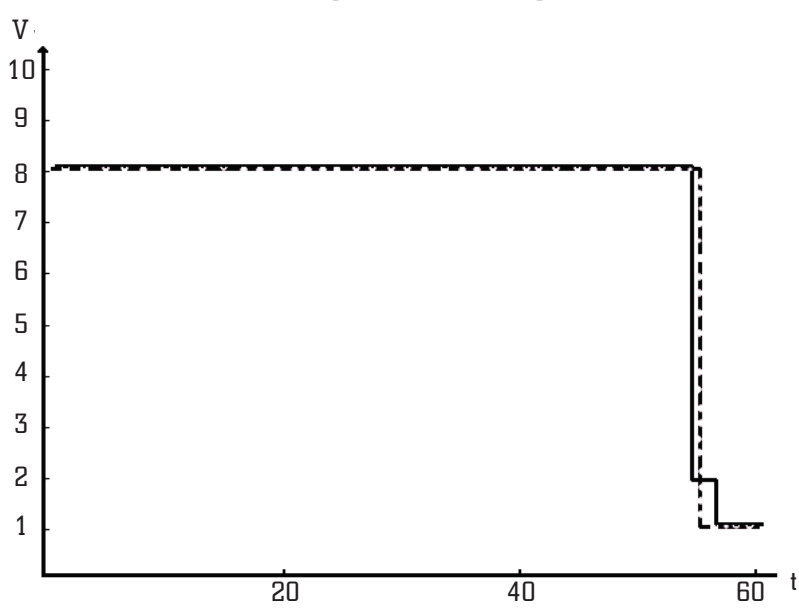

Fig. 2. Optimal speed control using conditional gradient method: $-v\left(t, T_{\text {on }}\right)$

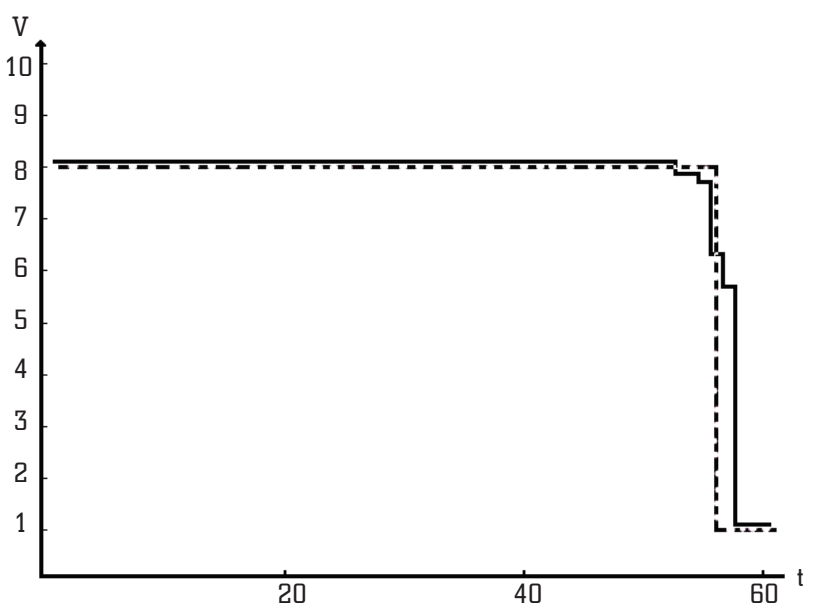

Fig. 3. Optimal speed control using gradient projection method: $-v\left(t, T_{a n}\right)$

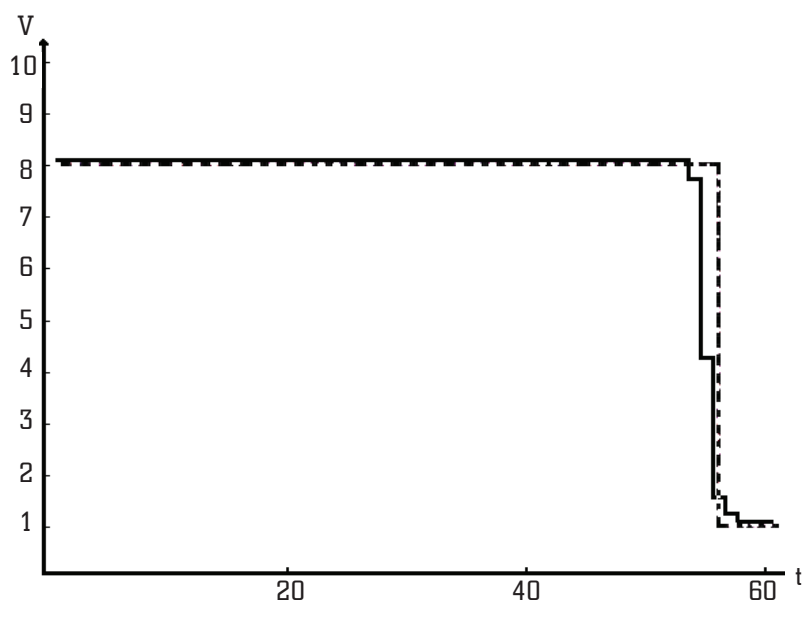

Fig. 4. Optimal speed control using gradient projection method: - . - . - v $v^{*}(t), \longrightarrow$

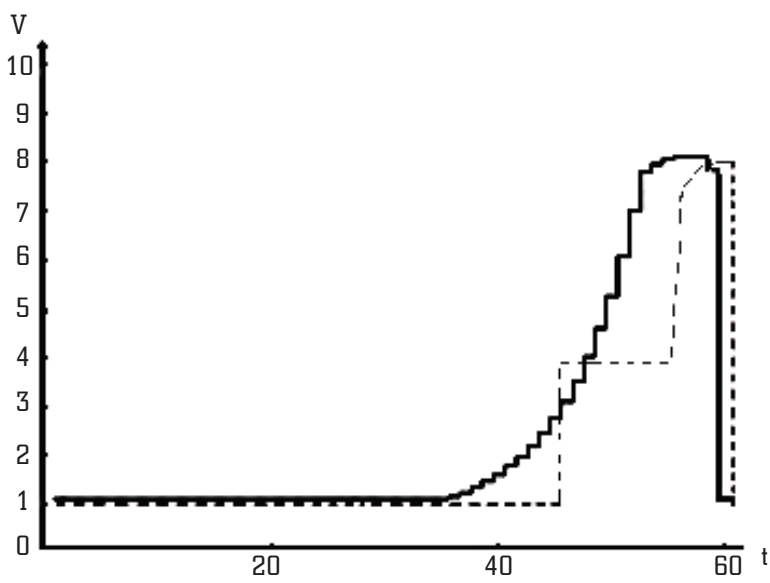

Fig. 5. Optimum speed control $v^{(2)}(t)$ : CGM (by the conditional gradient method), - GPM (gradient projection method)

As can be seen from Tables 2 and 3 , in order to achieve the specified accuracy in the performance problem, 6 iterations are required and $T_{\text {on }} \in(0.0525,0.06)$. In optimal control problems, the total number of iterations in option a by the conditional gradient method is 110 and the gradient projection method is 108 . In option $b$, the total number of iterations is CGM - 81, GPM - 64, i. e., the total number of iterations in the optimal control problem in method $b$ the choice of the initial approximation is much less than in variant a. In Fig. 1-4 shows the graphs of the optimal controls for speed, obtained in CGM and GPM, respectively. As can be seen from Fig. 1-4, the control-optimal controls obtained by both methods are fairly close to test controls. Calculations show that when $T^{(m)}$ sufficiently close to $T_{o n}$, the optimal controls are also close to relay functions. This property in the general case is not satisfied for optimal controls for $T^{(m)} \neq T_{\text {on }}$. For example, Fig. 5 shows the graphs of the optimal control $v^{(2)}(t)$ obtained by CGM and GPM. As can be seen from Fig. 5, these functions are not relay and quite different from $v^{*}(t)$ by the metric $C\left[0, T^{(2)}\right]$.

Tables 4 and 5 show the values of the functions $u^{*}(x)$ and $u\left(x, T_{o n}\right)$ at the grid nodes, these functions also agree well with respect to the metric $C\left(x_{c}, x_{R}\right)$.

Numerical experiments are also carried out in the case when the control-optimal controls have two switching points. However, the nature of the obtained results does not change. 
Table 4

Desired distribution $u^{*}(x)$

\begin{tabular}{|l|l|l|l|l|l|l|l|}
\hline \multicolumn{7}{|c|}{ The values of the desired temperature at the grid nodes } \\
\hline 1.0000 & 1.1139 & 1.1823 & 1.2311 & 1.2690 & 1.3000 & 1.3486 & 1.4162 \\
\hline 1.4988 & 1.5842 & 1.6366 & 1.6086 & 1.4861 & 1.3514 & 1.2583 & 1.2310 \\
\hline 1.2786 & 1.4037 & 1.6068 & 1.8878 & 2.2456 & 2.6756 & 3.1664 & 3.6907 \\
\hline 4.1892 & 4.5447 & 4.5608 & 3.9929 & 3.2476 & 2.2521 & 1.7027 & 1.4222 \\
\hline 1.2814 & 1.2110 & 1.1758 & 1.1406 & 1.1054 & 1.0702 & 1.0351 & 1.0000 \\
\hline
\end{tabular}

Table 5

Temperature distribution $u\left(x, T_{o n}\right)$

\begin{tabular}{|l|l|l|l|l|l|l|l|}
\hline \multicolumn{7}{|c|}{ Temperature values at the optimum time } \\
\hline 1.0000 & 1.1607 & 1.2571 & 1.3259 & 1.3793 & 1.4230 & 1.4913 & 1.5856 \\
\hline 1.6982 & 1.8027 & 1.8136 & 1.6954 & 1.4258 & 1.1956 & 1.0469 & 0.9842 \\
\hline 1.0046 & 1.1057 & 1.2877 & 1.5517 & 1.8987 & 2.3276 & 2.8313 & 3.3883 \\
\hline 3.9469 & 4.3951 & 4.5275 & 4.0577 & 3.3292 & 2.3091 & 1.7365 & 1.4428 \\
\hline 1.2952 & 1.2213 & 1.1844 & 1.1475 & 1.1106 & 1.0737 & 1.0368 & 1.0000 \\
\hline
\end{tabular}

As can be seen from Tables 1-5 and Fig. 3-5, the proposed algorithm gives fairly accurate results and can be used to determine the optimal parameters of heat conduction processes.

\section{SWOT analysis of research results}

Strengths. The proposed algorithm can be used to determine the optimal regime and time of thermal conductivity processes in inhomogeneous media. This algorithm contributes to: saving time; process optimization; increase the productivity of oil wells; increase the speed of calculation.

Weaknesses. The disadvantages of this method include the complexity of the calculation.

Opportunities. Thanks to the introduction of this method in the oil industry, an increase in oil recovery of the field to $40 \%$ is expected.

Threats. To implement this method, additional equipment is necessary, and, accordingly, it is money costs. Highly qualified personnel are also required to work with this equipment.

\section{Conclusions}

1. To solve the problems with the use of first-order optimization methods and finite differences on non-uniform grids, analytical formulas are obtained for the components of the gradient vector of the functional with respect to controllable functions.

2. A method is proposed for selecting initial approximations for optimal controls and a step in time at each iteration, which makes it possible to accelerate the calculation process. To achieve the specified accuracy, the speed problem required 6 iterations and $T_{\text {on }} \in(0.0525,0.06)$.

3 . Based on the analysis of the results of numerical experiments, the influence of various parameters on the iterative process is investigated and recommendations for the use of the proposed algorithm are worked out. In optimal control problems, the total number of iterations in option a by the conditional gradient method is 110 and the gradient projection method is 108. In option b, the total number of iterations is CGM - 81, GPM - 64, i. e., the total number of iterations in the optimal control problem in method $b$ the choice of the initial approximation is much less than in variant a. The optimal speed control, obtained by both methods, is close enough to test controls. Numeri- cal experiments are also carried out in the case when the control-optimal controls have two switching points. However, the nature of the results obtained does not change.

\section{References}

1. Surguchev, M. P. Vtorichnye i tretichnye metody uvelicheniia nefteotdachi plastov [Text] / M. P. Surguchev. - Moscow: Nedra, 1985. - 308 p.

2. Vurzhe, J. Termicheskie metody povysheniia nefteotdachi plastov [Text] / J. Vurzhe, P. Surno, M. Kombrarnu. - Moscow: Nauka, 1989. - 422 p.

3. Huseynov, S. I. Chislennoe reshenie zadach optimal'nogo upravleniia protsessami neizotermicheskoi fil'tratsii [Text]: Phd thesis / S. I. Huseynov. - Baku, 1986. - 142 p.

4. Tihonov, A. N. Uravneniia matematicheskoi fiziki [Text] A. N. Tihonov, A. A. Samarskii. - Moscow: Nauka, 2004. -755 p.

5. Yegorov, Y. V. Some problems in the theory of optimal control [Text] / Y. V. Yegorov // USSR Computational Mathematics and Mathematical Physics. - 1963. - Vol. 3, No. 5. P. 1209-1232. doi:10.1016/0041-5553(63)90108-3

6. Egorov, A. N. Teoriia upravleniia [Text] / A. N. Egorov. Moscow: Fizmatlit, 2004. - 504 p.

7. Vasil'ev, F. P. Metody optimizatsii [Text] / F. P. Vasil'ev. Moscow: Faktorial Press, 2002. - 824 p.

8. Schittkowski, K. Numerical solution of a time-optimal parabolic boundary-value control problem [Text] / K. Schittkowski // Journal of Optimization Theory and Applications. - 1979. Vol. 27, No. 2. - P. 271-290. doi:10.1007/bf00933231

9. Vasil'ev, F. P. Iterative methods for solving time optimal problems for parabolic equations [Text] / F. P. Vasil'ev // USSR Computational Mathematics and Mathematical Physics. - 1970. Vol. 10, No. 4. - P. 171-190. doi:10.1016/0041-5553(70)90013-3

10. Samarskii, A. A. Chislennye metody matematicheskoi fiziki [Text] / A. A. Samarskii, A. V. Gulin. - Moscow: Nauka «Nauchnyi mir», 2003. - 316 p.

11. Huseynov, S. I. O chislennom reshenii zadachi bystrodeistviia neizotermicheskoi fil'tratsii [Text] / S. I. Huseynov, A. Yu. Shariati // Izvestiia ANA. Seriia: fiziko-tehnicheskih i matematicheskih nauk. - 1999. - No. 3-4. - P. 44-48.

12. Huseynov, S. I. Numerical solution to the optimal speed-inAction problem for a heat conduction process with phrase constraints [Text] / S. I. Huseynov, S. Y. Qasimov // 24th Mini EURO Conference On Continuons Optimization and Information-Based Technologies in The Financial Sector (MEC EurOPT 2010). - Szur, Turkey, 2010. - P. 120-123.

13. Huseynov, S. I. Ob odnom metode resheniia zadachi optimal'nogo upravleniia protsessom termovozdeistviia na neftianoi plast [Text] S. I. Huseynov, O. M. Manafly, Sh. N. Ahmedov // Izvestiia Vysshih tehnicheskih uchebnyh zavedenii Azerbaidzhana. - 2000. - P. 65-68

14. Quseynov, S. I. On numerical Solution to an optimal Control Problem with constraint on the state for a parabolic equation [Text] / S. I. Quseynov, S. R. Kerimova // The 5th International Conference on Control and Optimization with Industrial applications. - Baku, 2015. - P. 94-97.

\section{ЧИСЛЕННОЕ РЕШЕНИЕ ЗАДАЧИ НА ОПТИМАЛЬНОЕ БЫСТРОДЕЙСТВИЕ С ФАЗОВЫМ ОГРАНИЧЕНИЕМ ДЛЯ ОДНОГО ПАРАБОЛИЧЕСКОГО УРАВНЕНИЯ}

Рассмотрен численный метод решения задачи на оптимальное быстродействие с фазовым ограничением для параболического уравнения с переменными коэффициентами, описывающего процессы теплопроводности в неоднородных пористых средах. Численная реализация алгоритма осуществлена методом конечных разностей на неравномерной сетке. Предлагаемый метод может быть применен для оптимального определения параметров процессов теплопроводности и диффузии в неоднородных средах.

Ключевые слова: параболическое уравнение, задача быстродействия, оптимальное управление, штрафной функционал, градиент функционала.

Huseynov Saftar Ilyas, PhD, Associate Professor, Department of General and Applied Mathematics, Azerbaijan State University of Oil and Industry, Baku, Azerbaijan, e-mail: huseynovsi@mail.ru, ORCID: http://orcid.org/0000-0002-7133-1152

Qasimov Sardar Yusub, PhD, Associate Professor, Department of General and Applied Mathematics, Azerbaijan State University of Oil and Industry, Baku, Azerbaijan, e-mail: sardarkasumov1955@mail.ru, ORCID: http://orcid.org/0000-0001-6650-1965 